\title{
Role of international and national standards in improving quality of life in urban environments in Sri Lanka
}

\author{
P H Ganiesha Jayamini De Silva ${ }^{1, a^{*}}$ \\ ${ }^{1}$ Standardization Division, Sri Lanka Standards Institution, \\ No 17, Victoria Place, \\ Elvitigala Mawatha, \\ Colombo 08, Sri Lanka \\ a ganiesha@slsi.lk
}

\begin{abstract}
Urbanization is a global societal trend where the proportion of people living in cities increases while the proportion of people living in the country side diminishes. Sri Lanka is in the phase of development after the end of civil war. For the past few years, Sri Lankan cities are urbanizing at an unprecedented scale and expected to rise further in future. Therefore, we are facing many challenges to ensure the development in a sustainable manner and to guarantee the high standard of living to all citizens.
\end{abstract}

Standards contribute sense of urgency to improve urban quality of life by improving energy efficiency, increasing resource efficiency, increasing public safety, planning urban development, developing services and infrastructure, improving transport system, intelligent use of resources, creating more livable environment, reducing impact to bio diversity and ecosystem and acting to mitigate climate change.

Keywords: Urbanization, Standards, Quality of life, Sustainable, Smart city

\section{Introduction}

At present, more than half of the world's population resides in urban areas and United Nation projections suggest that this number will swell to about $60 \%$ by 2030 and more than 6 billion people, almost $66 \%$ will be living in urban areas by 2050 (United Nations, Department of Economic and Social Affairs, 2014). As far as Sri Lanka is concerned, urban areas are home to $20 \%$ of the population and urban dwellers are expected to grow by $40 \%$ in 2030 and $50 \%$ by 2050 as people search for a better quality of life (Central Bank of Sri Lanka, 2014). To accommodate such a massive urbanization, each nation struggles to find smarter ways to complexities, increase efficiency, reduce expenses, improve the quality of lifeand strengthen urban communities. 
One out of 17 Millennium Development Goals adopted by world leaders at the United Nations Sustainable Development Summit in 2015 is to make cities inclusive, safe, resilient and sustainable. Along with this global concern, international and national standard bodies spotlights on developing and publishing relevant standards to support equitable, efficient and sustainable and resilient urban development.

After ending, 30 years war in Sri Lanka, government initiated rapid urban development projects to revitalize cities and create more urban space for its growing inhabitants due to escalating urban migration and sprawl. This has resulted significant negative impacts for health and quality of life in urban environment. In order to confront emerging issues and to achieve sustainable development, it would be of much significance to integrate standards in national urban development. And also standards would provide framework and incentive mechanism for propose, plan, implement and monitor sustainable urban development projects. It would give the much needed momentum to Sri Lanka in achieving vision of "sustainable and inclusive economic growth with equitable access to quality social services, strengthened human capabilities and reconciliation for lasting peace" by 2030.

Therefore, this paper has pointed out many crucial issues found with urbanization and their impact on urban quality of life and sustainable development. And also this paper illustrates how standards act as pillars in urban quality of life and sustainable urban development in Sri Lankan context.

\section{Urbanization in Sri Lanka}

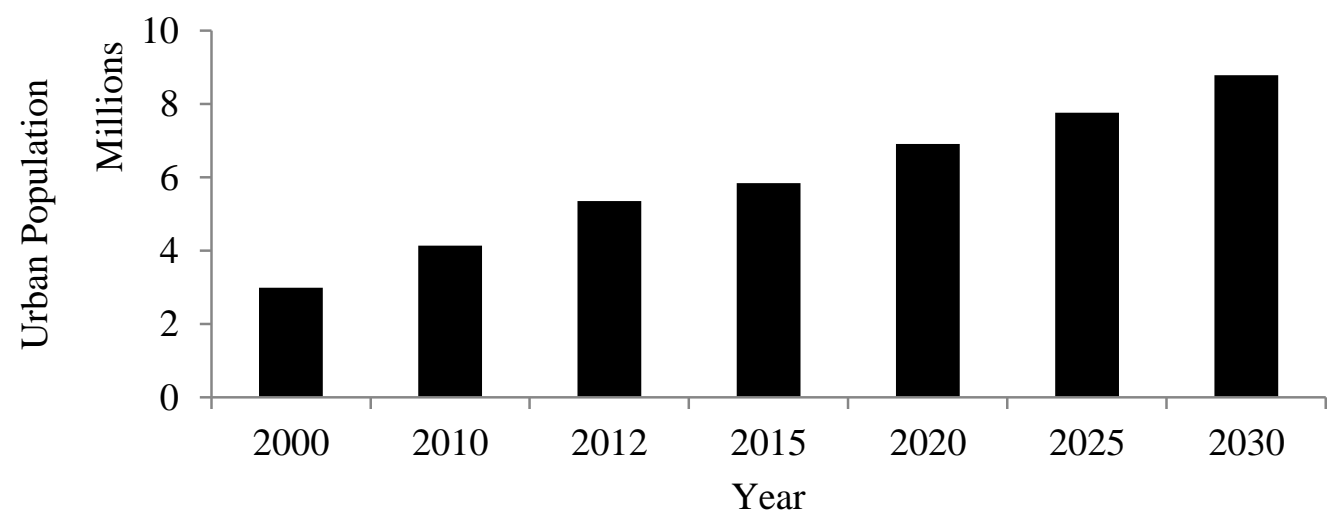

Fig. 1: Urban population growth in Sri Lanka (2000-2030)

(Source: Western Region Megapolis Master Plan 2015-2030)

The degree of urbanization is considered as an indicator of economic development of a country and living standards of the people (Uduporuwa, 2010). Urbanization provides new jobs and new opportunities for millions of people, deliver many public services whilst being center of innovation and technology and has contributed to poverty eradication efforts and to join the ranks of richer nations.

Sri Lanka economy transitioned from a previously predominant ruralbased agriculture economy towards a more urbanized economy. More than $80 \%$ of Sri 
Lanka's industries operate in close proximity to urban areas and $70 \%$ of GDP is generated by urban economy (Central Bank of Sri Lanka, 2014). Unlike primary sectors, many secondary and tertiary sectors are boosted to develop via the urbanization process and most sectors' specialization occurs when urbanization is in an advanced phase.

\section{Quality of life and sustainable development in urban context}

The World Health Organization has defined quality of life as "an individual's perception of their position in life in background of the culture and value systems in which they live and in relation to their goals, expectations, standards and concerns". Quality of life encompasses different things for different inhabitants, including: wholesome food, clean environment, wellbeing, wealth, betterpublic services and infrastructure, more satisfaction in work-life balance, emotional fulfillment in relationships and security. People choose to live in urban areas so they can have a better quality of life. They want to be at the heart of economic activity, and to have more job opportunities and other social and economic advantages. However, city living brings a range of challenges. Overcrowding, traffic pollution and noise and industrial emissions are just a few of the challenges that have to be constantly monitored and addressed to achieve a high quality of life.

The World Commission on Environment and Development defines sustainable development as "meeting the needs of the present without compromising the ability of future generations to meet their own needs'. Idea of sustainable development launched by the World Summit on Environment and Development of 1983 and the Earth Summit of 1992, redefined ecological sustainability as a key word in urban planning. Sustainable development cannot be achieved without significantly transforming the way we build and manage our urban spaces. The sustainable development of urban areas encapsulates equilibrium between environmental, social and economic sustainability and sustained for an unforeseeable future (Shen et al., 2011; Munasinghe 2010).

The urban environment influences physical, social and mental wellbeing. Therefore a healthy, safe and vibrant environment is indispensable to urban quality of life. People need to breathe clean air, have access to clean drinking water, low noise level, green spaces, adequate housing, availability of basic services, infrastructure, safety and security, promoting equality, increase accessibility for persons with disabilities and preservation of historic, spiritual, culturally significant buildings are key contributors to a better quality of life in urban areas.

\section{Urbanization problems and urban climate resilience}

An increasing number of people are migrating from rural to urban area every day putting pressure to exploitation of resources and increases demand for land, housing, energy, infrastructure, public services as well as for environment. High rate of traffic fatalities, long daily commutes, traffic congestion, large scale spreading of environmental pollution, overuse of non-renewable natural resources, energy consumption, 
malnutrition, increasing number of slums and shanties, danger, social inequalities, waste, inadequate or outdated infrastructure and lack of public services to the poor are common noticeable problems in urban areas since last few years and ultimately contributed to degradation of quality of urban living (Ileperuma, 2000; Abeygunawardane et al., 2011; Munasinghe, 2013; Subasinghe, 2015). Climate change and disasters can also aggravate social inequalities and quality of life in urban areas (Institute of Town Planners Sri Lanka, 2015).

In recent times, the threat of landslides loom largely over densely populated urban areas in the hilly parts of Sri Lanka. A study of National Building Research Organization has revealed that 35 large and medium sized towns in central highland are threatened with landslide due to indiscriminate land use and building construction. Urban areas in Sri Lanka experienced recurrent heavy flooding recently mainly due to unplanned urban development, ad hoc building construction, arbitrary filling of wetland, reservations and floodplain, blocking and narrowing of drainage paths and flood retention areas. The most of underserved settlements were located in low lying areas more vulnerable to flooding than the rest of the urban population but also caused life in the urban areas in general to come to a virtual halt. Furthermore, due to the haphazard nature and unhygienic conditions of the slums and shanties, the people living in them are at high risk of hazards such as fire, disease and epidemics. According to the Sri Lankan Disaster Management Centre, 425,000 people have been affected, 104 people are known to have died and 99 people are still missing due to severe flooding and numerous landslides caused in May, 2016. It is eminent that there would be much bigger disasters in the foreseeable future in urban areas if sustainability is ignored and destruction of the environment continues.

\section{Standards towards improving urban quality of life}

Lot of ongoing projects and policies are focusing to address and regulate increasing urbanization aligned issues. Maintaining sustainable urban environment is vital to achieve much needed sustainability goal. International and national standard bodies also has already identified its necessity for future and playing leading role in creation of smart and sustainable cities toward improves the quality of life in urban citizens. The successful implementation of the series of standards serve as a basis for evaluation of the urban development projects, an effective tool to foster urban development and tailor toward more sustainable and resilient communities.

Urban areas need common methodologies to measure and monitor progress of delivering urban services and quality of life and also provide clear guidance for sustainable development and resilience urban environment. SLS (Sri Lanka Standards) 1508: 2015 "Sustainable development in communities- Indicators for city services and quality of life" will enable cities to work with set of data indicators to measure city's social, economic, and environmental performance, share best practices, experience and knowledge from other cities globally and help cities to better manage and find out future oriented innovate solutions which is recognized by international entities. Such solutions are often referred to as "Smart". Indicators such as depression, ethnic disparities, violence, crime rates, mental frustration, loss of community identity, community sharing, 
social wellbeing, cultural integrity and diversity are mostly disregarded in earlier period and become overlooked dimensions in today's quality of life contexts due to in line with standards.

Urban areas are mainly responsible for staggering energy consumption and energy related greenhouse gas emissions. SLS ISO (International Organization for Standardization) 50001:2011 "Energy management systems- Requirements with guidance for use" and its supporting standards which are being implemented at present in Sri Lanka can be further adopted to improve energy performance and emission reduction in urban areas. Energy efficiency, alternative renewable sources of energy and green mobility such as electrical vehicles would enhance bright future in urban quality of life.

Buildings are the major source of demand for energy and construction materials produce significant amount of by product greenhouse gases that create significant impact on environment. It is important to renew the urban environment with energy saving, zero energy, energy efficient, sustainable and environmentally friendly buildings of long term value and longevity with compliance to applicable standards of ISO/Technical Committees 163 "Thermal performance and energy use in the built environment" and ISO/ Technical Committees 205 "Building environment design".

Solving transportation is the highest priority in the cities. Although various types of public transportation are provided in the cities, urban community still prefer to drive private vehicles resulting increased number of vehicles on the road every year. It creates more congestion, increasing greenhouse gas emissions, intensive environmental pollution within the urban limits and increased risk of obesity due to sedentary lifestyle (Department of Motor traffic, Sri Lanka). Urban planners will have to consider aspects such as improving mobility, environment friendly and more efficient transport system, development road network, integrate different mode of transportation, reduce emissions, more walkable and cyclable space for cyclists and pedestrians in future urban development policy framework. This could be fulfilled by implementation and compliance to series of ISO standards developed and published by ISO/ Technical Committees 204 "Intelligent transport system".

Excessive road traffic accidents have been reported in urban areas. Existence of ISO 39001:2012 "Road traffic safety management systems - Requirements with guidance for use" is believed to be a good tool in encouraging contributions towards road safety by reduces death and serious injury due to road accidents.

Infrastructureis improving living standards and addressing resource efficiency sometimes conflicts with a path to sustainability. As a result, it is imperative that infrastructures contribute to sustainability and resilience of communities more effectively and efficiently. ISO/Technical Specification 37151:2015 Smart community infrastructures - Principles and requirements for performance metrics provide requirements and recommendations relevant to performance metrics. The metrics in this standard will support urban managers in planning and measuring performance and also compare and select procurement proposals for products and services to improve 
community infrastructures. Therefore adhering to internationally agreed standards, is essential when integrate of various infrastructure systems into urban environment to ensure technologies make interoperable, safe and efficient. SLS 1507: 2015 "Smart community infrastructures- Review of existing activities relevant to metrics" address community infrastructures such as energy, water, transportation, waste, information and communication technology (ICT). Integration of the smart community infrastructure standards helps to improve the lifestyles of its citizens by reducing costs, increasing mobility, accessibility and reducing environmental pollutants.

The urban area will be equipped with ICT and the entirety of the urban area will be connected in order to control of resource usage, good governance, economic vitality, effective infrastructure, improve services, protection of environment, equitably development, security, social equity, sustainability toward better quality of life and effective performance. By improving the availability and quality of information and communications technology in urban area, we can ensure that people have access to information about what is happening in cities, sharing of data and find out ways of increasing sustainability. In this context, ISO/ International Electrotechnical Commission 27000 series standards provide practical tool to secure information and data.

Foremost role of SLS ISO 14001:2015 "Environmental management systems requirements with guidance for use" which is being adopted and implemented in Sri Lanka can be used to further enhance the urban environment to achieve quality of life in urban areas. Major initiative such as cleaner fuels, smart transport infrastructure, green building and promotion active living could be positively reduce all environmental challenges and crucial guidance to protect the environment. In line with standards provide path to encourage sustainable use of natural resources and safeguard the fragile ecosystems during the implementation of the development projects.

Another important aspect of urban development is beautification. During the thirty years of war in Sri Lanka, the natural beauty became obscured. Since the dawn of peace, projects are underway to create of eco parks to preserve the existing marshlands and provide sanctuary to the unique wildlife that inhabits these areas. Similarly, urban planners focus on the 'greenification' of urban areas (Perera, 2015), with ample green and blue spaceswhich contribute to encourage healthy living and social interaction among communities. Sugathapala and Jayathilake (2012) also emphasized boosting green infrastructure by promoting trees in streets, green walls and roofs, gardens and parks, wetlands and water bodies is a most obvious strategy that can be adopted on climate change impact in Sri Lankan scenario.

Urban resilience entails the ability of cities to prepare, respond and recover from natural and manmade crises with minimum damage to public safety and health, economy and security. Sri Lanka's urban areas are becoming more vulnerable to climate change and disasters. SLS ISO 31000 : 2016 "Risk management - Principles and guidelines" and SLS ISO 22320:2013 "Societal security - Emergency management - Requirements for incident response" provide answers to respond and recover incidents, emergencies and disasters by reducing vulnerability and play a useful role in 
creating more resilient cities. Efficient and sustainable land use, shifts towards low carbon economy, high efficiency technologies in optimal fashion, resource management practices, risk and vulnerability assessments, development and enforcement of building standards, environmental protection measures, recognition of hazard zones and real time information about developing crises need to be mainstreamed into urban plan is a win-win solution to mitigate the impacts of climate change and leading to an increase safety and security of community. It is essential that urban planners become more familiar with techniques and best practices that can be adopted to enhance urban resilience. This is a particularly pressing need in urban areas that have experienced haphazard planning and unauthorised construction activities over time.

\section{Sri Lanka Policy Framework for Smart Cities: Step towards a viable future}

Smart Growth becomes now part of the lexicon of urban planners with an interest in urban issues which is emerging in $21^{\text {st }}$ century. Across globe many countries are increasingly embracing the smart city concept, which essentially utilises digital infrastructure and services offer a potential way of effectively monitoring and managing physical and social resources in the city to increase quality of life, ensuring equal opportunities cohesion along with sustainable balance. Few countries are already experiencing the luxuries of improved services through the concept of a smart city.

As a nation, economic instability, deteriorating infrastructure, natural disasters, environmental pollution, social disintegration, crime and violence, urban blight and unmanaged urban areas are numerous challenges that we are facing today. As Sri Lanka looks towards the viable future, one of the most important aspects it needs to develop is the functionality of its cities. Governments understand these and to move one step ahead by introducing smart city vision for better urban area. The word "smart city" has created a big hype in Sri Lanka and encouraging for the country's future (Deheragoda, 2010). Smart cities will bring more benefits and value to the country, encouraging sustainable development and sustain our communities with sensible management of natural resources.

In 2015, Sri Lanka introduced concept of "Megapolis" which aim to drive economic growth and prosperity, social equity and harmony, environmental sustainability and individual happiness. A number of plans and projects to build "smart cities" are currently underway in Sri Lankan urban areas.Smart parking, smart mobility, real time information and management, clean drinking water, affordable housing, smart power grids that provide electricity as per the demand resulting in increased efficiency, smart street lighting, smart building, smart care, smart city maintenance, green environment, robust information technology connectivity and digitization, egovernance and many other smart characteristics would be plan to incorporate. Smart city enable transformation of the national economy into a predominantly knowledge based innovation driven economy via well interconnected, instrumented digital infrastructure. 
With SLS 1508, Sri Lankan cities would accurately benchmark city services and quality of life against other cities in the world, assess where they stand and analyze gap, how would improve their indicators over time and consistent tracking and accurate reporting of key performance indicators toward sustainable development. Standards also addressed most crucial urban environmental issues like storm water management, micro level drainage, hazardous waste disposal arrangements, growing industrial pollution, coastal erosion and threats to wetlands from garbage dumping besides reclamation.

\section{Summary}

Standards provide common platform to ensure environmental sustainability, preserving eco systems, resilient to climate change and natural disasters, improve services and optimize the functional efficiency in urban structure. Sri Lanka Standards Institution (SLSI) as national standard body of Sri Lanka having understood this global requirement and the necessity of adopting relevant international standards locally. It is fully geared to implement standards by working hand in hand with national urban policy framework 2015-2030. Aligned with international and national standards we could improve our quality of life in urban environment, performance in public value creation, high touristic fluxes and ultimately country will be able to drive forward to make a toptier country in the world. Well planned, managed and governed urban areas would provide safe, organized and enjoyable homes and work life for residents are in return who would yield higher productivity for Sri Lankan economy.

\section{References}

Abeygunawardane A.W.G.N., Dayawansa N.D.K. and Pathmarajha S., (2011), Socioeconomic Implications of Water Pollution in an Urban Environment A Case Study in Meda Ela Catchment, Kandy, Sri Lanka Tropical Agricultural Research, 22, 374 - 383

Central Bank of Sri Lanka (2014), Central Bank of Sri Lanka-Annual Report, 2014

Deheragoda K., (2010), Tools for sustainable urban development, Institute of Town Planners Sri Lanka -Annual session, 2010

Ileperuma, O.A., (2000), Environmental pollution in Sri Lanka: a review, Journal of the National Science Foundation of Sri Lanka. 28, 301-325.

International Standards Organization (2013), ISO Focus+ Smart cities, 4, 1, 8-32

Ministry of Megapolis and western development (2016), MEGAPOLIS- Western Region Master Plan, 2015-2030

Munasinghe H., (2010) Ecological paradigms in planning the livable city, International Conference on Sustainable Built Environment (ICSBE-2010)

Munasinghe J., (2013), Policies and issues in urban development in Sri Lanka, Sri Lanka Journal of Social Science, 36, 9-17

National Building Research Organization, (1994), Proceedings Volume I, National Symposium of Landslides, Sri Lanka

Perera E.L. S. J., (2015), Re-thinking of urban planning for sustainable development of communities in Sri Lanka in the context of 2030 development agenda: understanding the role of population dynamics, University of Colombo Annual Research Symposium2015

Shen L.Y., Ochoa J. J., Shah M. N., and Zhang X., (2011), The application of urban sustainability indicators - A comparison between various practices, Habitat International, 35, 17-29. 
Subasinghe W, (2015), Quality of Life Study on Slum Dwellers, International Journal of Scientific Research and Innovative Technology, 2, 36-65

Sugathapala K.C., and Jayathilake K.A.D.S.B., (2012), A Green Area Ratio for Sri Lankan Urban Areas, National Building Research Organization symposium 2012 on Sustainable Disaster Resilient Technologies

Uduporuwa R., (2010), An Analysis of Urban Growth and Urbanization in the Sabaragamuwa Province, Sri Lanka, Sabargamuwa University Journal, 9, 115-132

United Nations Department of Economic and Social Affairs, Population Division (2015), World Urbanization Prospects: The 2014 Revision 